\title{
IMPLEMENTASI WEBSITE E-COMMERCE PADA TOKO ONLINE BERLITAID MENGGUNAKAN METODE SEO DAN BUSINESS MODEL CANVASS
}

\author{
Bawono Bayu Aji Salim ${ }^{1)}$, Lauw Li Hin ${ }^{2)}$ \\ ${ }^{1}$ Sistem Informasi, Fakultas Teknologi Informasi, Universitas Budi Luhur \\ 1,2Jl. Raya Ciledug, Petukangan Utara, Kebayoran Lama, Jakarta Selatan 12260 \\ E-mail : bawonobayuaji6@gmail.com ${ }^{1)}$, lauw.lihin@budiluhur.ac.id ${ }^{2)}$
}

\begin{abstract}
Abstrak
Pesatnya perkembangan teknologi saat ini, persaingan bisnis semakin ketat terutama terhadap kebutuhan primer. Salah satunya BerlitaID, toko ini hanya ada dalam bentuk online yang menjual produk busana muslim wanita dengan model yang eksklusif, BerlitaID menjual produknya melalui sosial media instagram. Pemilik toko ini menginginkan memiliki website untuk toko online nya, dengan tujuan untuk bersaing dengan toko-toko lainnya yang telah memiliki website pribadi dalam menjalankan usahanya. Website ini bertujuan untuk mendapatkan kepercayaan yang lebih dari pelanggan, serta memudahkan proses transaksi, maka dirancanglah website berbasis PHP yang mudah digunakan dari sisi user maupun admin. Adapun metode yang digunakan dalam membangun website tersebut yaitu wawancara dengan pemilik toko, observasi jalan-nya proses bisnis, studi literatur berdasarkan jurnal-jurnal yang telah memiliki issn, serta BMC (Business Model Canvass) sebagai perancangan dari suatu bisnis yang ingin dikembangkan. Hasil dari penelitian ini berupa website ECommerce yang dibangun dengan menggunakan PHP untuk membangun kepercayaan yang lebih dari pelanggan, serta untuk mempermudah proses transaksi dan juga untuk mempermudah admin dalam proses pembuatan laporan setiap bulan. Website ini dibangun dengan tampilan yang mudah digunakan baik dari segi pelanggan maupun admin.
\end{abstract}

Kata kunci: Business Model Canvass, PHP, E-Commerce, website.

\section{PENDAHULUAN}

BerlitaID merupakan toko online yang menjual produknya melalui sosial media Instagram, toko ini berdomisili di Tangerang. Toko ini berkeinginan untuk memiliki website E-Commerce pribadi yang bertujuan untuk mendapatkan kepercayaan lebih dari pelanggan guna bersaing dengan toko online lainnya di bidang yang sama yang telah memiliki website pribadi. Dengan adanya website ini juga dapat mempermudah transaksi antara admin BerlitaID dengan customer. Dan juga website ini dibangun dengan menggunakan teknik SEO yang bertujuan untuk meningkatkan pendpatan.

Terdapat beberapa masalah yang dihadapi oleh BerlitaID, yaitu: pesaing-pesaing dari BerlitaID yang telah memiliki website pribadi dalam menjalankan usahanya, staff admin harus bekerja lebih untuk mengecek stok barang terlebih dahulu jika ada pelanggan yang memesan.

Adapun tujuan dan manfaat dari penelitian ini, yaitu : membangun website dengan memperhatikan kemudahan dan kenyamanan pelanggan dalam menggunakan website tersebut, mempermudah pelanggan melihat barang-barang yang baru dirilis, membuat fasilitas transaksi agar proses lebih cepat dan aman, menempatkan website pada indexing google, website dibangun dengan sistem $e$ - commerce dimana bentuk bisnis adalah B2C (Business to Customer).

E-Commerce merupakan salah satu bagian dari gaya hidup modern yang memungkinkan transaksi jual beli dilakukan secara online dan dapat dilakukan dimanapun dan kapanpun[1]. Dengan kata lain, $e$ commerce merupkan suatu toko modern yang menggunakan koneksi internet dengan tujuan untuk mempermudah pelanggan dalam bertransaksi.

Agar suatu website dapat dikategorikan sebagai E-Commerce maka diperlukan beberapa komponen yang harus ada, yaitu : produk, tempat untuk menjual (berupa domain dan hosting), cara menerima pesanan (berupa e-mail, sms, telepon, dan lainnya), cara pembayaran pesanan (cash, cek, bankdraft, dan lain sebagainya), metode pengiriman (paket pengirman ekspedisi), serta customer service (e-mail bisnis, telepon, chatting, FAQ, dan lain-lain) [1].

Sekarang ini sudah banyak toko-toko lain yang sudah menggunakan metode e-commerce dalam menjalankan bisnis-nya, tentu saja hal ini mengakibatkan website e-commerce kita menjadi sulit dicari didalam mesin pencari seperti google. Salah satu cara untuk memunculkan website kita di halaman mesin pencari yaitu dengan teknik SEO.

SEO sendiri merupakan teknik merekayasa mesin pencari agar menampilkan website kita berada 
pada urutan teratas, berdasarkan hasil pencarian yang kita targetkan. Para pebisnis online menerapkan teknik SEO terhadap website nya dengan harapan website tersebut dapat tampil di halaman pertama hasil pencarian alami. Jika website tersebut berada di halaman hasil mesin pencari maka dipastikan traffic atau pengunjung akan semakin ramai mendatangi website kita, maka diharapkan juga banyak yang membeli produk yang kita jual didalam website tersebut[2].

Terdapat dua jenis SEO, yaitu on-page dan offpage. On-page yaitu suatu kegiatan yang dilakukan terhadap halaman website agar mesin pencari dapat dengan mudah meng-index kata kunci yang ada dalam website tersebut, dapat berupa deskripsi produk, tag produk, nama produk, nama domain. Sedangkan off-page yaitu suatu kegiatan yang dilakukan diluar halaman website yang dapat mempengaruhi peringkat website sesuai dengan kata kunci yang ditargetkan, dapat berupa backlink melalui media sosial[2].

\section{METODE PENELITIAN}

\subsection{Metodologi Pengumpulan Data}

Teknik pengumpulan data berhubungan dengan masalah penelitian yang akan dicari solusinya. Penggunaan teknik dan alat yang tepat sangatlah penting guna menemukan solusi yang tepat dan akurat. Maka berikut adalah metode-metode yang dilakukan peneliti dalam mengumpulkan data :

\section{a. Wawancara}

Wawancara yaitu suatu teknik pengumpulan data yang dilakukan dengan cara tanya jawab langsung dengan narasumber yang terkait untuk mendapatkan informasi terkait dengan masalah yang terjadi. Wawancara dilakukan dengan secara singkat dan padat namun jelas agar narasumber tidak terasa terganggu. Pertanyaan-pertanyaan yang diajukan, harus sesuai dengan permasalahan yang terkait. Wawancara adalah salah satu cara yang sangat ampuh untuk memahami suatu kebutuhan[5].

b. Observasi

Observasi dapat dilakukan dengan cara mengamati objek-objek secara langsung yang terkait dengan proses berjalan-nya suatu bisnis[6]. Observasi ini dilakukan untuk mendapatkan datadata tentang situasi dan kondisi yang sedang terjadi, serta mendapat gambaran jelas apa saja yang sedang terjadi terhadap objek penelitian.

\section{c. Studi Pustaka}

Studi pustaka merupakan kegiatan mencari informasi terdahulu yang sesuai dengan tema penelitian. Dapat menggunakan referensi dari jurnal, buku, karya ilmiah tugas akhir yang terdahulu lalu disimpulkan guna mendapatkan informasi yang sesuai.

\subsection{Teknik Analisis Data}

Terdapat beberapa teknik yang dipakai peneliti untuk menganalisa sistem yang sedang berjalan serta mempelajari sistem yang akan dipakai.

a.) Activity Diagram

Activity diagram menggambarkan aktifitasaktifitas, objek, state, transisi state dan event[4]. Diagram ini digunakan peneliti untuk melihat bagaimana alur berjalan-nya dari suatu proses bisnis yang sedang berjalan disuatu sistem.

b.) Use Case Diagram

Use case diagram digunakan untuk mengetahui peran para pelaku bisnis yang terjadi disuatu sistem[4].

c.) Rancangan Layar

Rancangan layar diperlukan untuk mengetahui bagaimana tampilan layar pengguna pertama kali.

d.) Sequence Diagram

Sequence diagram digunakan untuk mengetahui bagaimana suatu sistem beroperasi yang disusun berdasarkan urutan waktu[4].

e.) Class Diagram

Class diagram dipakai untuk mengetahui relasi antar tabel basis data yang digunakan untuk menjalankan suatu sistem usulan[4].

f.) Business Model Canvass

Business model canvass digunakan untuk mempermudah pemilik bisnis untuk membangun dan mengembangkan bisnis atau perusahaan yang dijalankan[3].

\section{HASIL DAN PEMBAHASAN}

\subsection{Business Model Canvass}

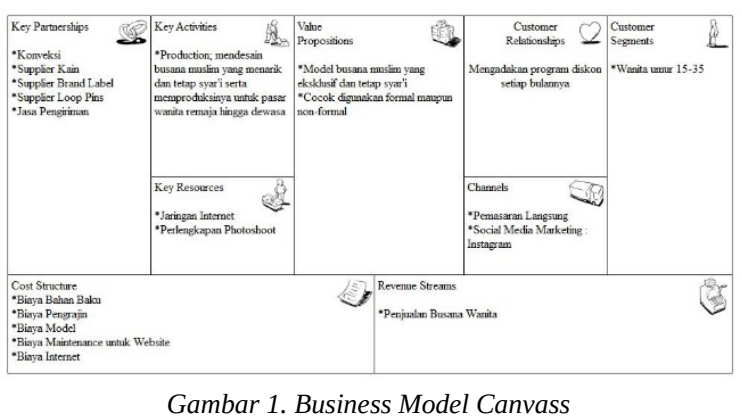

Terdapat beberapa elemen yang terdapat di dalam business model canvass, yaitu :

a) Key Partnership

BerlitaID menjalin kerja sama dengan beberapa supplier, mulai dari konveksi sebagai pembuat produk yang akan dijual, supplier kain sebagai bahan baku utama produk yang akan dijual, supplier brand label, supplier loop pins.

b) Key Activities 
Mendesain busana muslim yang menarik dan juga memperhitungkan dari segi syar'i-nya yang akan dibuat, serta memproduksinya secara eksklusif serta handmade untuk pasar wanita remaja hingga dewasa.

c) Value Propositions

BerlitaID adalah suatu brand yang menjual berbagai busana muslim untuk wanita remaja hingga dewasa. Tidak seperti produk busana muslim lainnya yang bermodelkan itu-itu saja, kami membuat desain busana yang menarik namu tetap menjaga syar'i jika dipakai. Busana ini dapat digunakan untuk formal maupun non-formal.

d) Customer Relationship

BerlitaID setiap bulannya akan mengadakan program diskon untuk produk tertentu.

e) Customer Segment

Target pasar yang dituju BerlitaID adalah wanita dengan rentang umur 15-35 tahun.

f) Key Resources

Terdapat beberapa hal yang dapat mempengaruhi jalannya bisnis berlitaID, yaitu jaringan internet, perlengkapan photoshoot, serta admin untuk instagram dan juga website. Dari ketiga hal tersebut, yang sangat dibutuhkan adalah jaringan internet, bila tidak ada jaringan internet bisnis tidak akan berjalan.

g) Cost Structure

Adapun biaya produksi yang dikeluarkan berlitaID untuk setiap produknya, yaitu biaya bahan baku produksi, pengrajin pembuat produk, model sebagai promosi produk, internet sebagai media promosi, serta maintenance website.

h) Channels

Pemasaran yang dilakukan berlitaID, yaitu pemasaran langsung secara door to door, dan juga melalui media sosial instagram.

i) Revenue Streams

Pendapatan yang didapat oleh berlitaID berasal dari penjualan busana muslim.

\subsection{Activity Diagram}

Terdapat beberapa activity diagram usulan, yaitu :

a) Activity Diagram Pembelian Barang

Pelanggan membuka website berlitaID, lalu pelanggan melihat-lihat produk yang ingin dibeli, setelah itu klik tombol preview jika ingin melihat lebih lanjut, lalu akan muncul keterangan produk yang telah dipilih, jika ingin memilih produk dan memasukkan nya kedalam shoping cart klik tombol "shop now", jika tidak klik tombol home dan akan memilih kembali barang yang ingin di inginkan. Setelah selesai memilih barang, akan muncul ringkasan order. Jika ingin melanjutkan ke pembayaran, pelanggan mengklik procceed to checkout, namun jika ingin melanjutkan berbelanja klik continue shoping. Pastikan jumlah barang yang ingin dipesan tidak melebihi stok barang yang tersedia.

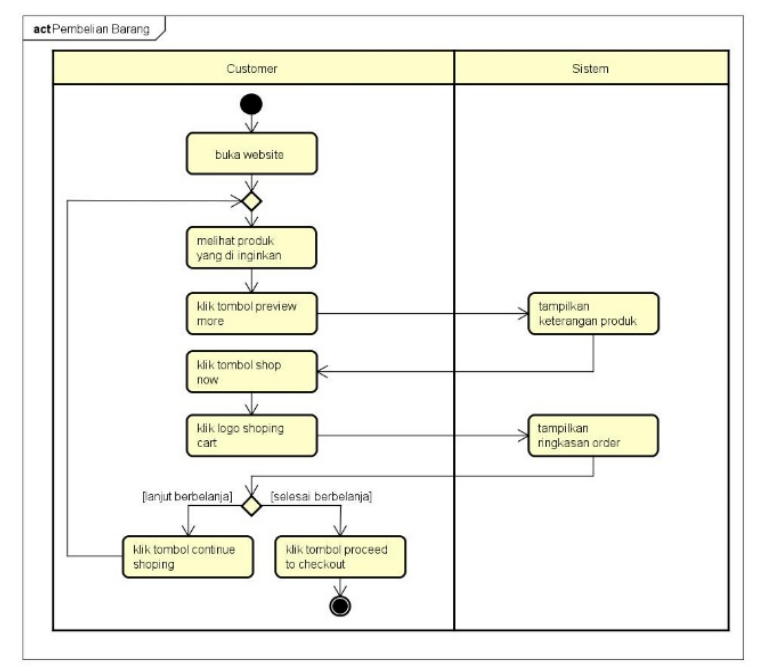

Gambar 2. Activity Diagram Pembelian Barang

\section{b) Activity Diagram Checkout}

Setelah pelanggan klik tombol proceed to checkout, sistem akan mengecek sesi login. Jika sudah login akan muncul form checkout, lalu customer akan mengisi form yang tersedia dan juga memilih kurir dan paket pengiriman yang di inginkan. Jika belum login, customer tidak dapat melakukan proses checkout dan harus login terlebih dahulu.

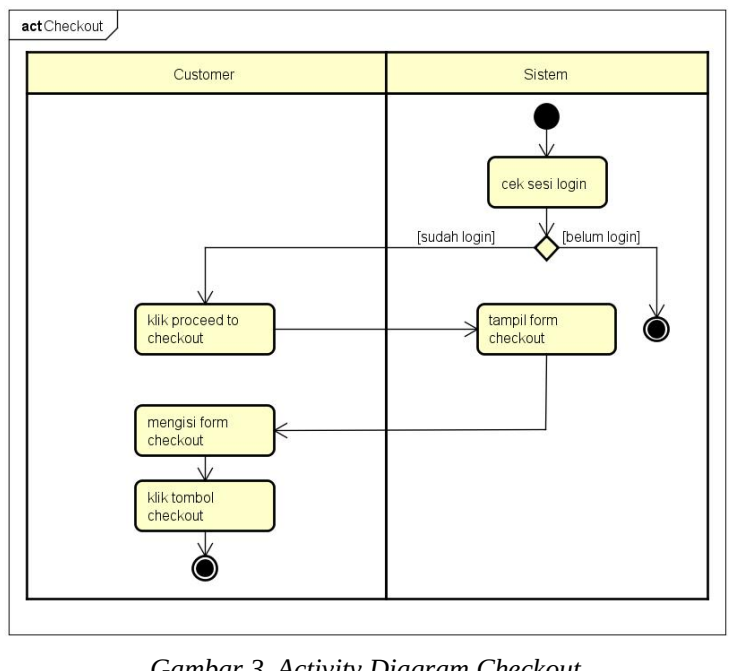

c) Activity Diagram Pembayaran

Setelah melakukan proses checkout, pelanggan akan mendapat email dan membayar sesuai tagihan yang diterima ke nomor rekening yang tertera di website. Setelah membayar pelanggan melakukan konfirmasi pembayaran dengan mengklik konfirmasi pembayaran di menu user. Lalu pilih transaksi yang 
ingin dikonfirmasi, setelah itu meng-upload bukti pembayaran, klik tombol konfirmasi jika telah selesai.

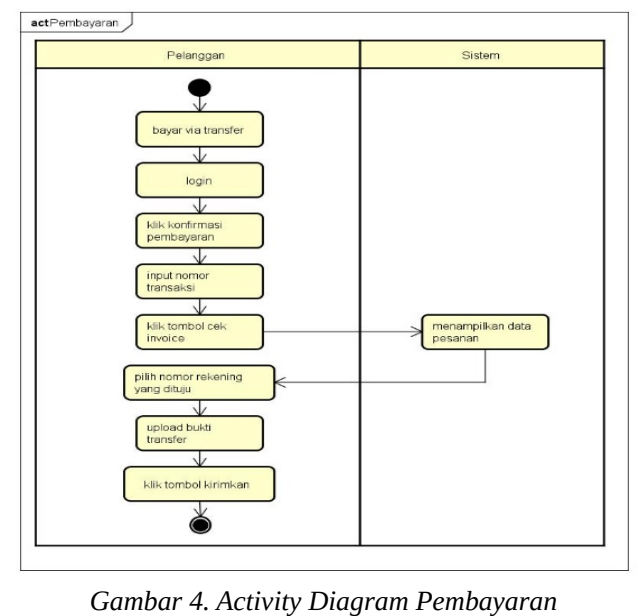

\subsection{Use Case Diagram}

Terdapat beberapa use case diagram usulan, yaitu :

a) Use Case Diagram Master

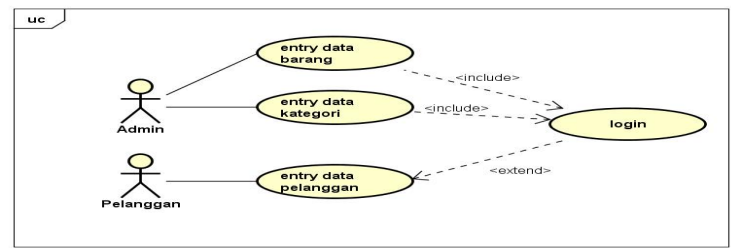

Gambar 5. Use Case Diagram Master

b) Use Case Diagram Transaksi

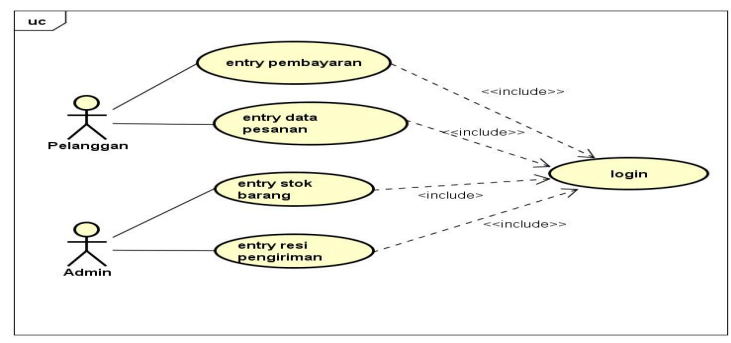

Gambar 6. Use Case Diagram Transaksi

c) Use Case Diagram Laporan

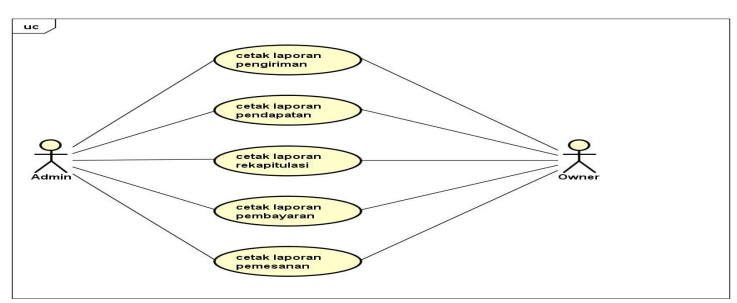

Gambar 7. Use Case Diagram Laporan

\subsection{Class Diagram}

Adapun class diagram yang terdapat didalam sistem usulan

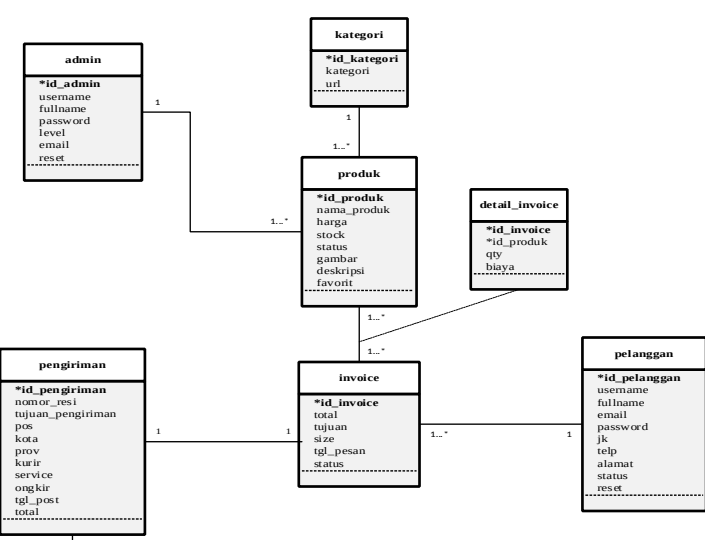

\subsection{Rancangan Layar}

Sebelum sistem dibangun, sebaiknya melakukan perancangan tampilan layar sistem tersebut terlebih dahulu. Dengan tujuan agar pemakai sistem tersebut mengetahui terlebih dahulu bagaimana rupa awal dari tampilan layar yang akan mereka terima nantinya, dan bila tidak berkenan akan bisa segera diperbaiki sebelum sistem tersebut diresmikan akan dipakai. Adapun beberapa rancangan layar yang terdapat pada berlitaID, yaitu :

a) Rancangan Layar Menu Utama

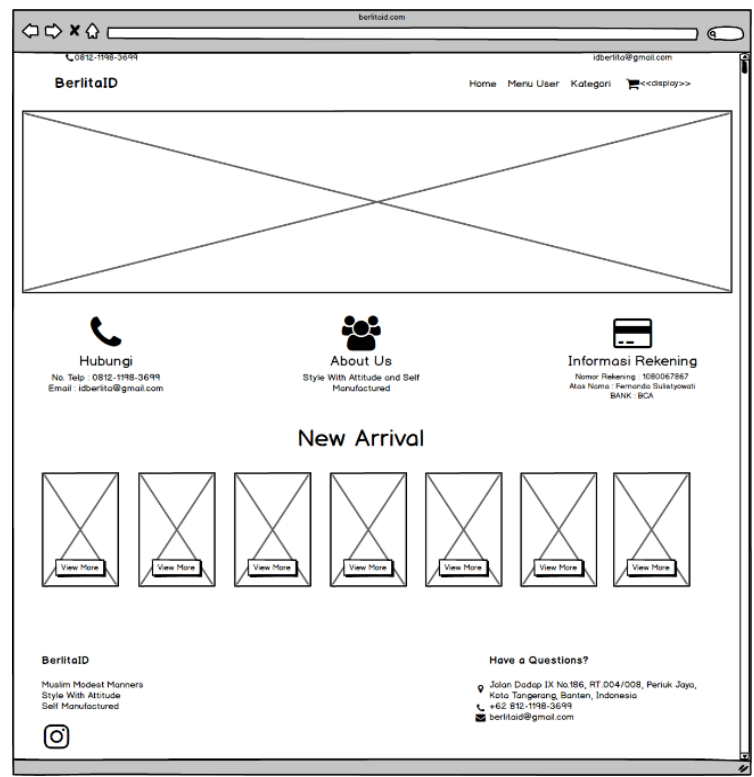

Gambar 9. Rancangan Layar Menu Utama 
b) Rancangan Layar Menu Cart

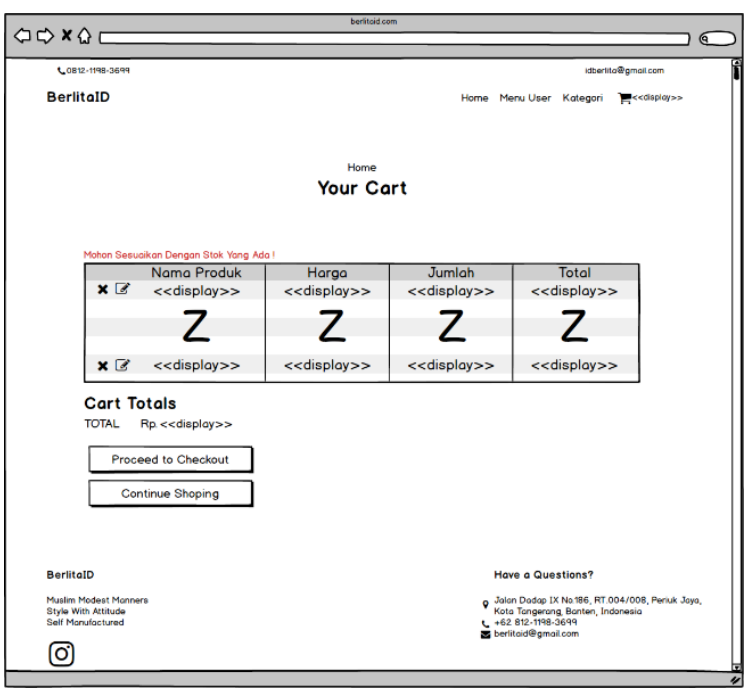

Gambar 10. Rancangan Layar Menu Cart

c) Rancangan Layar Detail Produk

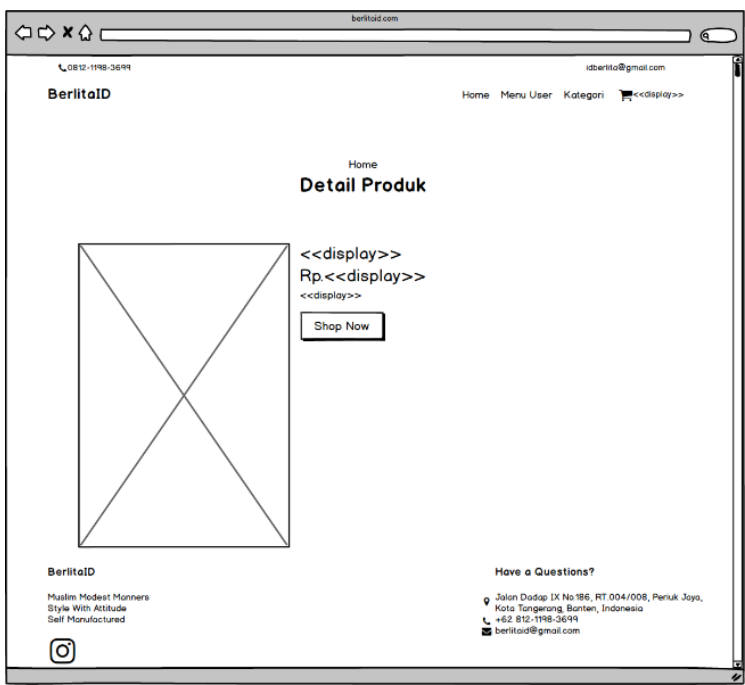

Gambar 11. Rancangan Layar Detail Produk

d) Rancangan Layar Detail Transaksi

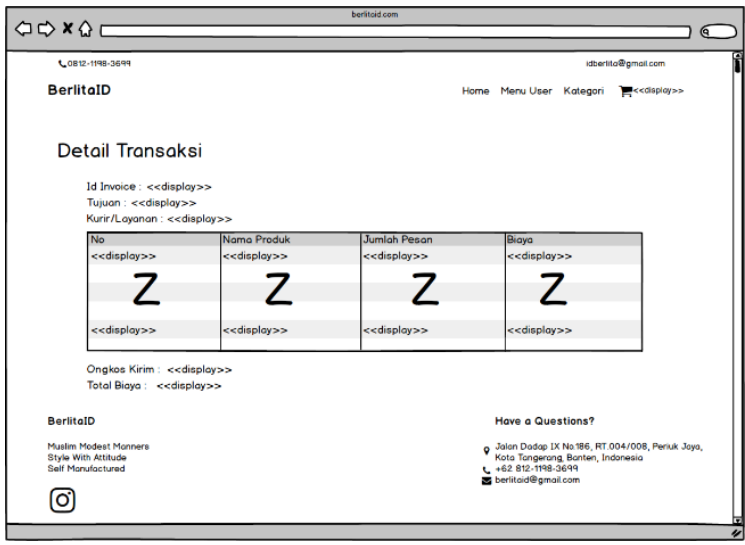

Gambar 12. Rancangan Layar Detail Transaksi

\subsection{Sequence Diagram}

Sequence diagram dirancang untuk mengetahui alur bagaimana suatu sistem berjalan. Terdapat beberapa sequence diagram yang telah peneliti buat berdasarkan use case diagram yang telah dibuat, yaitu :

a) Sequence Diagram Master Barang

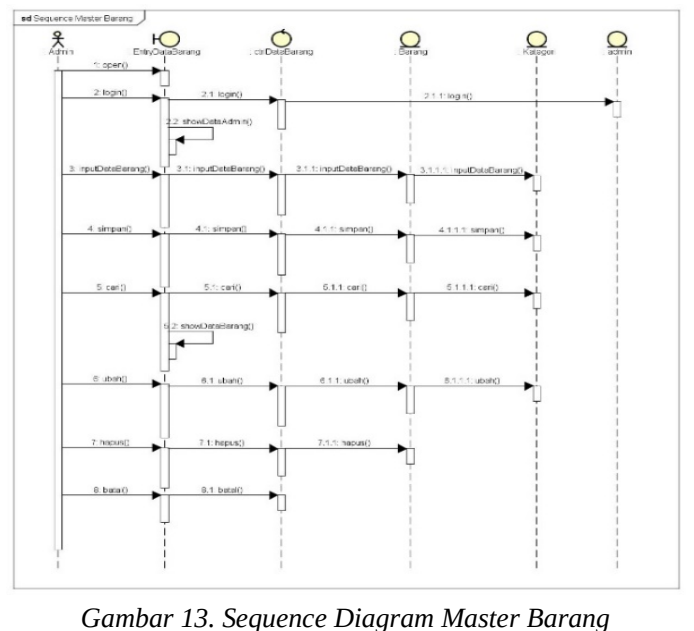

b) Sequence Diagram Master Pelanggan

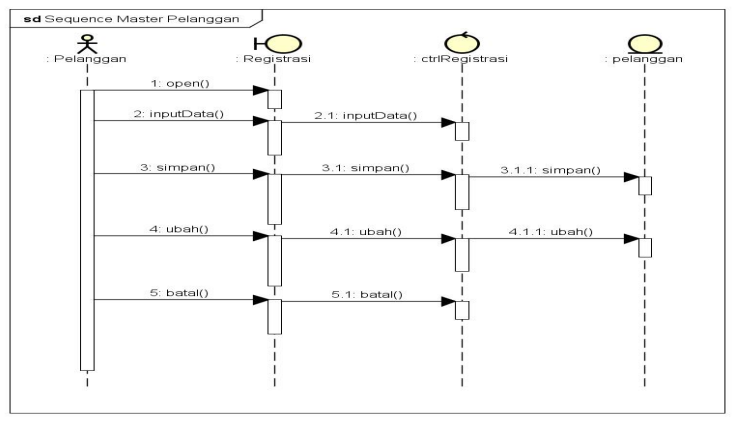

Gambar 14. Sequence Diagram Master Pelanggan

c) Sequence Diagram Pemesanan Barang

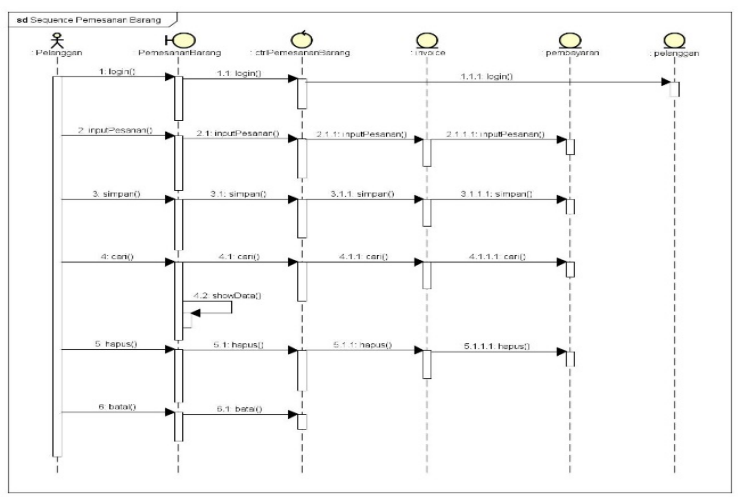

Gambar 15. Sequence Diagram Pemesanan Barang

d) Sequence Diagram Pembayaran 


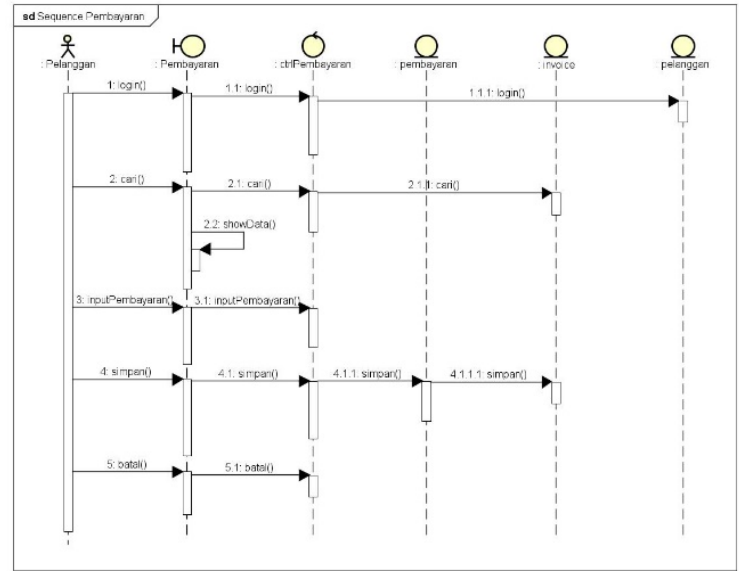

Gambar 16. Sequence Diagram Pembayaran

\subsection{Teknik SEO}

Terdapat beberapa teknik SEO yang dilakukan peneliti dalam membangun website berlitaID, diantaranya yaitu :

a) Meta Keyword

Meta keyword ini digunakan didalam script PHP yang dibuat oleh peneliti, atribut ini berfungsi sebagai kata kunci bagi mesin pencari dalam mengindex halaman website.

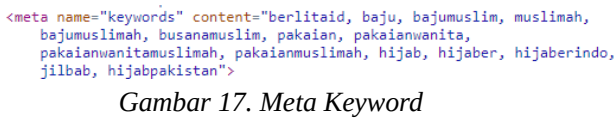

b) Meta Robots

Meta robots ini digunakan didalam script PHP yang peneliti buat, atribut ini berfungsi untuk mengontrol pengindeksan mesin pencari dan meta ini berlaku untuk semua mesin pencari tidak hanya google saja.

\section{Gambar 18. Meta Robots}

\section{c) SEO Off-Page}

SEO off-page ini peneliti lakukan dengan cara mencantumkan alamat website ke dalam akun instagram berlitaID, dan juga nama-nama produk yang ada didalam website sama dengan nama-nama produk yang ada di instagram.

\section{KESIMPULAN}

Setelah mempelajari permasalahan yang ada, dapat diambil beberapa kesimpulan yaitu :

a) Dengan adanya sistem E-Commerce, maka BerlitaID dapat bersaing dengan yang kompetitor dalam hal mendapatkan kepercayaan pelanggan. b) Memudahkan admin dalam mengecek stok barang.

c) Memudahkan proses transaksi.

d) Dengan sistem E-Commerce ini, admin dapat mengetahui dengan mudah segmentasi pasar yang tertuju.

e) Website yang dibangun menggunakan metode user friendly, yang artinya tampilan dari website tersebut akan mudah digunakan.

\section{DAFTAR PUSTAKA}

[1] Hidayat, Taufik, Panduan Membuat Toko Online dengan OSCommerce, Mediakita, Jakarta. 2008

[2] Setiawan, Agus. Cara Mudah Banjir Order Melalui Internet Marketing. Malang: Madza. 2011

[3] Osterwalder, A., Pigneur, Y. Business Model Generation. New Jersey: John Wiley \& Sons Inc. 2010

[4] Haviluddin. Memahami Penggunaan UML (Unified Modelling Language). Jurnal Informatika Mulawarman. 6(1). 2011, pp. 1-15.

[5] Supriyati. Metode Penelitian. Bandung: Labkat Press Unikom. 2011.

[6] Arikunto. Prosedur Penelitian Suatu Pendekatan Praktek. Jakarta : PT. Rineka Cipta. 2006. 